\title{
JUDGING ANTIGONE IN OLD AGE: (NEURO)PSYCHOLOGY AND LAW IN THE TWENTY-FIRST CENTURY
}

\author{
Vaitsa Giannouli \\ Aristotle University of Thessaloniki, Greece \\ E-mail: giannouliv@hotmail.com
}

\begin{abstract}
Although medicine, psychology and law have a long history behind them (Frank, 1930; Kapardis, 2009), and several issues may emerge at the interface of these scientific fields, new specific disciplines have been created to fill the research gap, such as legal psychology and forensic psychology (Taylor, 2019). In this direction, forensic neuropsychology combines not only psychometric testing, but also interviews, behavioral observations, and record reviews as additional sources of information for answering cognitive functioning questions in legal and forensic settings (Fink, 2007). Additionally, the emergence of a new promising interdisciplinary field, neurolaw, explores how neuroscience and advanced techniques can be used in the legal system (Meynen, 2014; van Dongen \& Franken, 2019). Although there are still a plethora of topics that are not adequately described and need further research in neuropsychology, several attempts have been made to collect data for different research questions linked to this complex field (Canter \& Žukauskiene, 2019). Methods and protocols regarding the processes of criminal profiling, the examination of cognitive biases in legal decision making, interrogations and confessions, detection of deception, eyewitness memory and false memories-distortions, cognition and emotions of child witnesses, and competence to stand trial, are still not clear (Bornstein \& Miller, 2016; Brewer \& Douglass, 2019).

Neuropsychology and its applications to the legal forum, still disregard areas that are lacking cross-cultural investigation by (neuro)psychologists, such as crime and legal issues in the process of assessment of intellectually disabled individuals (Giannouli, 2016). A more socially oriented approach may include the research of attitudes towards legal issues in adults with cognitive deficits, and specifically in older adults (Giannouli, 2014; Giannouli \& Tsolaki, 2015; Giannouli, Tegos, Zilakaki, \& Tsolaki, 2019), as well as the objective testing of law-related capacities in elders suffering from different types of cognitive deficits (Giannouli, 2018; Giannouli, Stamovlasis, \& Tsolaki, 2018; Giannouli \& Tsolaki, 2014) or different forms of dementias (Giannouli \& Tsolaki, 2019a). Given the rising numbers of elders worldwide (Giannouli, 2017), the evaluation of competence for this population may be of utmost importance in the next years, as competence and the law-related problems can take a number of different forms, such as assessment of specific capacities concerning the capacity for medical consent, capacity for sexual
\end{abstract}


consent, financial capacity, testamentary capacity, driving capacity and capacity for independent living (Giannouli \& Tsolaki, 2011; Giannouli \&Tsolaki, 2014). The need to use imaging techniques and numerical data linked to biological functions as predictive factors of different forms of lawrelated capacities (Giannouli \& Tsolaki, 2019b), emphasizes the fact that the question 'Are we there yet?', still triggers the process of questioning ourselves about 'What we can and cannot conclude'. In addition to that, an unanswered question across different cultural settings is how to communicate and translate the knowledge of neuropsychology and relevant results to the judges, lawyers, as well as the general public in order to inform policy and practice, as well as the public opinion (Postal, 2019), while the ethical dimensions when clinical-therapeutic issues are involved in legal procedures are heavily debated (McLachlan, 2019).

\section{References}

Bornstein, B. H., \& Miller, M. K. (Eds.). (2016). Advances in psychology and law. New York: Springer International Publishing.

Brewer, N., \& Douglass, A. B. (Eds.). (2019). Psychological science and the law. New York: Guilford Publications.

Canter, D., \& Žukauskiene, R. (2017). Psychology and law: Bridging the gap. UK: Routledge.

Fink, J. W. (2017). Beyond the tests: Record review, interview, and observations in forensic neuropsychology. In S. S. Bush, G. J. Demakis, \& M. L. Rohling (Eds.), APA handbook of forensic neuropsychology (pp. 295-308). Washington, DC: American Psychological Association.

Frank, J. (1930). Law and the modem mind. New York: Brentano's.

Giannouli, V. (2014). What do Greeks believe about elders and mental capacity? AGORA International Journal of Juridical Sciences, 8(3), 1-5.

Giannouli, V. (2016). Crime and legal issues among intellectually disabled individuals. In R. T. Gopalan (ed.), Handbook of research on diagnosing, treating, and managing intellectual disabilities (pp. 346-369). IGI Global.

Giannouli, V. (2017). Alzheimer's disease: Psychosocial dimensions of a modern plague? Encephalos, 55, 33-38.

Giannouli, V. (2018). Elder abuse and consent capacity: Our collective nemesis?. In R. T. Gopalan (ed.), Social, psychological, and forensic perspectives on sexual abuse (pp. 207-221). IGI Global.

Giannouli, V., Stamovlasis, D., \& Tsolaki, M. (2018). Exploring the role of cognitive factors in a new instrument for elders' financial capacity assessment. Journal of Alzheimer 's Disease, 62(4), 1579-1594. doi: 10.3233/ JAD-170812.

Giannouli, V., Tegos, T., Zilakaki, M., \& Tsolaki, M. (2019). Elders and mental capacity: Using a qualitative approach to examine views on independence and protection across the Balkans. Hellenic Journal of Nuclear Medicine, 22(2), 122-139.

Giannouli, V., \& Tsolaki, M. (2011). Competency and dementia: A challenge of today. Neurology, 20(6), 12-19.

Giannouli, V., \& Tsolaki, M. (2014). Legal capacity of the elderly in Greece. Hellenic Journal of Nuclear Medicine, 17(1), 2-6.

Giannouli, V., \& Tsolaki, M. (2015). A neglected drama for elders: Discrepancy between self-perception and objective performance regarding financial capacity in patients with cognitive deficits. Psychological Thought, 8(2), 142-147. https://doi.org/10.5964/psyct.v8i2.130.

Giannouli, V., \& Tsolaki, M. (2019a). Depression and financial capacity assessment in Parkinson's disease with dementia: Overlooking an important factor? Psychiatriki, 30(1), 66-70. https://doi.org/10.22365/ jpsych.2019.301.66.

Giannouli, V., \& Tsolaki, M. (2019b). Are left angular gyrus and amygdala volumes important for financial capacity in mild cognitive impairment? Hellenic Journal of Nuclear Medicine, 22, 160-164.

Kapardis, A. (2009). Psychology and law: A critical introduction. UK: Cambridge University Press.

McLachlan, K. (2019). Clinical forensic psychology and law. UK: Routledge. 
74 Meynen, G. (2014). Neurolaw: Neuroscience, ethics, and law. Review essay. Ethical Theory and Moral Practice, 17(4), 819-829. https://doi.org/10.1007/s10677-014-9501-4.

Postal, K. (2019). Testimony that sticks: The art of communicating psychology and neuropsychology to juries. Oxford University Press.

Taylor, S. (2019). Forensic psychology: The basics. UK: Routledge.

van Dongen, J. D., \& Franken, I. H. (2019). Neuroscience in forensic psychiatry and psychology: An introduction to the special issue. International Journal of Forensic Mental Health, 18(3), 179-186. https://doi.org/ 10.1080/14999013.2019.1652708.

Received: October 30, 2019

Accepted: December 04, 2019 